\title{
Hydrogen sulphide removal in waste water treatment plant by compact oxidative scrubbing in Aquilair Plus ${ }^{\mathrm{TM}}$ process
}

\author{
P.-F. Biard*, A. Couvert**, C. Renner*, P. Zozor*, S. Bassivière*, J.-P. Levasseur*** \\ * Anjou Recherche-Veolia Environnement, Chemin de la Digue, BP 76, 78603 Maisons-Laffitte, France \\ (E-mail: pierre-francois.biard@veolia.com ; christophe.renner@veolia.com ; philippe.zozor@veolia.com ; \\ sebastien.bassiviere@veolia.com) \\ **ENSCR, Sciences Chimiques de Rennes - Chimie Ingénierie des Procédés, CNRS, 263 avenue du Général \\ Leclerc, 35700 Rennes, France \\ (E-mail: annabelle.couvert@ensc-rennes.fr) \\ ***Direction technique Veolia Eau, L'Aquarène, 1 place Montgolfier, 94417 Saint Maurice, France \\ (E-mail: jean-pierre.levasseur@veoliaeau.fr)
}

\begin{abstract}
Recently, the development of a high voidage contactor, named Aquilair Plus ${ }^{\mathrm{TM}}$, has demonstrated high efficiency for chemical scrubbing of hydrogen sulphide. Liquid and gas phases flow at co-current and high velocity, leading to a great dispersion of the liquid and then to an enhancement of the mass transfer rate by comparison with classical packed towers. This study focused on the results which obtained at semi-industrial scale with the Aquilair Plus ${ }^{\mathrm{TM}}$ process on a waste water treatment plant located in France. The scrubbing liquid consisted of a sodium hypochlorite alkaline solution. At once, pressure drop, $\mathrm{H}_{2} \mathrm{~S}$ removal and reagents consumption were followed. The influence of the superficial gas velocity, liquid-to-gas mass ratio (L/G), $\mathrm{pH}$, hypochlorite concentration of the scrubbing liquid and $\mathrm{H}_{2} \mathrm{~S}$ inlet concentration was characterised. $\mathrm{H}_{2} \mathrm{~S}$ removal percentages higher than $90 \%$ could be easily achieved with a moderate pressure drop (< 40 mbar). Both hydrodynamic and chemical conditions proved to influence performances. Reagents consumptions slightly higher than the predicted ones were measured.
\end{abstract}

Keywords Absorption; Chemical scrubbing; Hydrogen sulphide; Odour; Process intensification

\section{INTRODUCTION}

Environmental concern pertaining to olfactory nuisances is on the increase. Indeed, odorous pollution is the second reason for complaints after noise. Waste water treatment plants (WWTPs), among other facilities, can cause odour emissions likely to generate significant annoyance in the neighbourhood (Frechen, 2004). Hydrogen sulphide is the predominant odorous molecule associated with sewage (Gostelow et al., 2001) and its formation in sewers has been extensively studied (Matos and de Sousa, 1992; Nielsen et al., 1998). In order to treat these odorous atmospheres, some classical processes are implemented: biofilters can be an alternative but the most common used are packed towers, in which pollutants are removed by chemical scrubbing (Bonnin, 1991; Chen et al., 2001). This technology has been showing good results for many years, but has also revealed high investment and working costs (Couvert et al., 2008b). Indeed, the long residence time necessary for a good functioning of the process and the hydrodynamic behaviour inside the packed column imply the construction of high and wide towers. Comparing to physical absorption, chemical scrubbing offers several advantages. The irreversible degradation of the pollutant in the liquid allows to regenerate the scrubbing solution and to maintain a driving force to achieve mass transfer. Moreover, if the degradation kinetics is fast or instantaneous, a mass transfer acceleration can occur (Coulson and Richardson, 1996; Perry and Green, 1997; Levenspiel, 1999) and the pollutant bulk concentration is equal to 0 . This drives to an enhancement of the mass transfer rate. According to the Whitman double film theory, the pollutant is fully consumed in the liquid film at the gas-liquid interface and the $\mathrm{H}_{2} \mathrm{~S}$ transferred flow ( $\mathrm{dN}$ in mol.s ${ }^{-1}$ ) is given by Eq. (1):

$$
\mathrm{dN}=\mathrm{k}_{\mathrm{L}} \mathrm{a}^{0} \mathrm{E} \frac{\mathrm{p}_{\mathrm{H}_{2} \mathrm{~S}}}{\mathrm{H}_{\mathrm{H}_{2} \mathrm{~S}}} \mathrm{dV}
$$


Where $\mathrm{k}_{\mathrm{L}}$ is the liquid film mass transfer coefficient $\left(\mathrm{m} \cdot \mathrm{s}^{-1}\right)$, $\mathrm{a}^{0}$ is the volumetric interfacial area $\left(\mathrm{m}^{2} \cdot \mathrm{m}^{-3}\right), \mathrm{p}_{\mathrm{H}_{2} \mathrm{~S}}$ is the $\mathrm{H}_{2} \mathrm{~S}$ partial pressure $(\mathrm{Pa}), \mathrm{H}_{\mathrm{H}_{2} \mathrm{~S}}$ the $\mathrm{H}_{2} \mathrm{~S}$ Henry's constant and $\mathrm{dV}$ an elementary volume. E represents the enhancement factor and is equal to the rate of $\mathrm{H}_{2} \mathrm{~S}$ transferred when the reaction occurs divided by the rate of $\mathrm{H}_{2} \mathrm{~S}$ transferred when no reaction occurs. E depends on the Hatta number (Ha), which represents the maximum pollutant conversion in the liquid film compared with its maximum transport through the film (Van Krevelen and Hoftijzer, 1948) and can be estimated by Eq. (2):

$\mathrm{Ha}=\frac{\sqrt{\gamma \mathrm{kC}_{\mathrm{R}} \mathrm{D}_{\mathrm{H}_{2} \mathrm{~S}, \mathrm{~L}}}}{\mathrm{k}_{\mathrm{L}}}$

Where $\gamma$ represents the stoechiometric coefficient of the reaction between the reagents $\mathrm{R}$ and $\mathrm{H}_{2} \mathrm{~S}, \mathrm{k}$ is the kinetic constant of the reaction $\left(\mathrm{M}^{-1} \cdot \mathrm{s}^{-1}\right)$ and $\mathrm{D}_{\mathrm{H}_{2} \mathrm{~S}, \mathrm{~L}}$ is the diffusion coefficient of $\mathrm{H}_{2} \mathrm{~S}$ in water $\left(\mathrm{m}^{2} \cdot \mathrm{s}^{-1}\right)$. Ha higher than 3 indicates that the reaction is fast and occurs in the liquid film where the pollutant is fully consumed. Considering the very short contact time in the Aquilair Plus ${ }^{\mathrm{TM}}$, a high value of $\mathrm{E}$ and consequently of $\mathrm{Ha}$, is required.

Recently, a study has emerged to the development of a high voidage contactor, named Aquilair Plus ${ }^{\mathrm{TM}}$, specially adapted to intense chemical scrubbing. The contactor is composed of a patented wire mesh packing structure where liquid and gas flow at co-current and high velocity $\left(>10 \mathrm{~m} \cdot \mathrm{s}^{-1}\right)$ (Sanchez et al., 2007c). The device allows a great dispersion of the liquid into fine droplets by impact of this phase on the wire mesh, and then to an enhancement of the mass transfer rate by comparison with classical packed towers. At the laboratory scale, it has been shown that an increase of the superficial gas velocity $\left(\mathrm{U}_{\mathrm{SG}}\right)$ and in a minor extent of the superficial liquid velocity $\left(\mathrm{U}_{\mathrm{SL}}\right)$ leads to better interfacial area $\left(a^{0}\right)$ and liquid mass transfer coefficient $\left(\mathrm{k}_{\mathrm{L}} \mathrm{a}^{0}\right)$ due to a higher energy loss (Sanchez et al., 2007a). The gas residence time can be reduced to less than $50 \mathrm{~ms}$ instead of about 1 or 2 seconds in packed towers to treat efficiently $\mathrm{H}_{2} \mathrm{~S}$ in $\mathrm{NaOCl}$ caustic aqueous solution (Sanchez et al., 2007b; Couvert et al., 2008a). An economical evaluation demonstrated a reduction of investment and working costs comparing to packed towers comprised between 15 and $40 \%$ (Couvert et al., 2008b). These good performances were attributed to fast kinetic of both dissociation reactions due to $\mathrm{HO}^{-}$and oxidation due to $\mathrm{NaOCl}$. Indeed, $\mathrm{H}_{2} \mathrm{~S}$ is an acid compound ( $\mathrm{pKa}_{1}=7$ and $\mathrm{pKa}_{2} \approx 12$ at $298 \mathrm{~K}$ ) (Cadena and Peter, 1988). In $\mathrm{NaOCl}$ caustic solution, $\mathrm{H}_{2} \mathrm{~S}$ reacts with $\mathrm{NaOCl}$ to form $\mathrm{SO}_{4}{ }^{2-}$ as a final product. The first step of this degradation could be the dissociation of $\mathrm{H}_{2} \mathrm{~S}$ in $\mathrm{HS}^{-}$or its oxidation by hypochlorite. The complete oxidation of one mole of $\mathrm{H}_{2} \mathrm{~S}$ consumes 4 moles of $\mathrm{NaOCl}$ and 2 moles of $\mathrm{NaOH}$ (Eq. 3):

$\mathrm{H}_{2} \mathrm{~S}+4 \mathrm{NaOCl}+2 \mathrm{NaOH} \longrightarrow \mathrm{Na}_{2} \mathrm{SO}_{4}+4 \mathrm{NaCl}+2 \mathrm{H}_{2} \mathrm{O}$

A first scale-up of the process was realised with a half-sized industrial pilot plant designed to treat a polluted gas flowrate of $4000 \mathrm{~m}^{3} \cdot \mathrm{h}^{-1}$ (Couvert et al., 2008b). Nevertheless, results were quite disappointing by comparison to the laboratory, since lower $\mathrm{H}_{2} \mathrm{~S}$ removals were obtained for similar pressure drops. This phenomenon could be explained by lower wall effects in the industrial plant, which implied a higher $U_{S G}$ to achieve a fully dispersed flow. Consequently, several improvements were realised, the main ones were the decrease of the contactor diameter from $300 \mathrm{~mm}$ to $200 \mathrm{~mm}$ and the design of a new wire mesh packing structure. The decrease of the diameter was done to reach higher $U_{S G}$ without changing the fan. The new packing structure presents a high void fraction (> 99.9\%) but the spatial arrangement of the mesh offers a higher tortuosity.

This study focuses on the results achieved after these changes. At once, the pressure drop $(\Delta \mathrm{P})$, the $\mathrm{H}_{2} \mathrm{~S}$ removal and the reagent consumption were determined. The influence of the superficial gas velocity $\left(\mathrm{U}_{\mathrm{SG}}\right)$, liquid-to-gas mass ratio $(\mathrm{L} / \mathrm{G}), \mathrm{pH}$, sodium hypochlorite concentration of the scrubbing liquid $([\mathrm{NaOCl}])$ and $\mathrm{H}_{2} \mathrm{~S}$ inlet concentration $\left(\left[\mathrm{H}_{2} \mathrm{~S}\right]_{\mathrm{G}, \mathrm{i}}\right)$ was characterised. 


\section{MATERIAL AND METHODS}

\section{Contactor}

The contactor is the key element of the process. It consists of a wire mesh structure of $200 \mathrm{~mm}$ diameter (void fraction $>99.9 \%$ ). The initial height of the packing was $600 \mathrm{~mm}$ but after the first experiments, the packing was compressed on $500 \mathrm{~mm}$.

\section{Reactor Set-up (Figure 1a)}

The pilot was controlled thanks to an Allen Bradley automation system (Rockwell automation, USA) and piloted with a PcVue supervision. The polluted air was pumped from the extraction pipe of a French WWTP with a fan (AEIB, France). By opening a valve placed before the fan, it was possible to dilute polluted air with clean air to study influence of the inlet $\mathrm{H}_{2} \mathrm{~S}$ concentration $\left(\left[\mathrm{H}_{2} \mathrm{~S}\right]_{\mathrm{G}, \mathrm{i}}\right.$ in ppmv: Part Per Million Volumic). The gas flowrate $\mathrm{Q}_{\mathrm{G}}$ was measured and controlled thanks to a Pitot Tube Deltabar S PMD70 (Endress Hauser, Germany) and a frequency variator (Allen Bradley). The liquid injection upstream the contactor was insured by a spray nozzle SpiralJet (Spraying System, USA). Pressure upstream and downstream the contactor was measured thanks to two pressure sensors Cerabar S PMC71 (Endress Hauser, Germany). A 400 L tank allowing to store the scrubbing liquid and to separate the gas-liquid mixture was placed downstream the contactor. A droplet separator has been added downstream the tank before emission in atmosphere (Horus Environnement, France). The storage tank was filled with ground water previously softened. Reagents ( $\mathrm{NaOCl}$ and $\mathrm{NaOH}$ provided by Brenntag, Germany) were pumped from $1000 \mathrm{~L}$ tanks to the storage tank thanks to two Gamma L metering pumps (Prominent, USA). The scrubbing liquid was recirculated to the top of the contactor through a MDFL pump (Iwaki, Japan) and the liquid flowrate was controlled thanks to an electromagnetic flowmeter Promag 10P (Endress Hauser, Germany). Moreover, the storage tank was equipped with two level sensors BSM (Bamo, France).

Figure 1. a) Reactor set-up b) Regulated parameters during a typical experiment.


\section{Regulation}

A bypass located after the recirculation pump allows the measurement of the $\mathrm{pH}$, redox, temperature and conductivity of the scrubbing liquid ( $\mathrm{pH}$ and temperature sensor: Orbisint CPS 11; redox sensor: Orbisint CPS 12; conductivity sensor: Indumax CLS 50; all provided by Endress Hauser). The $\mathrm{pH}$ and $\mathrm{NaOCl}$ concentration of the scrubbing liquid, clean water supply and drain were regulated respectively by (Figure 1b):

$-\mathrm{pH}$ measurement (when the low threshold is reached, injection of $\mathrm{NaOH}$ begins until the high threshold is reached);

-Redox measurement (when the low threshold is reached, injection of $\mathrm{NaOCl}$ begins until the high threshold is reached); 
-Conductivity measurement (when the high threshold is reached, drain of the storage tank begins until the low level is reached. Then, clean water is supplied until the high level is reached).

\section{Measurement methods}

The concentration of the $\mathrm{NaOH}$ commercial solution was regularly checked by colorimetric titration (phenolphthalein) with sulphuric acid and the concentration of the commercial solution of $\mathrm{NaOCl}$ by the iodometric method. Moreover, at the beginning and the end of each experiment, the concentration of the scrubbing liquid in the storage tank was measured. $\mathrm{Th} \mathrm{H}_{2} \mathrm{~S}$ concentration was continuously measured upstream and downstream the Aquilair Plus ${ }^{\mathrm{TM}}$ by two electrochemical sensors Polytron (Dräger, Germany).

\section{RESULTS AND DISCUSSION}

\section{Pressure drop inside the contactor}

The Pressure drop across the contactor was measured for $\mathrm{U}_{\mathrm{SG}}$ varying between 5.3 and $24.7 \mathrm{~m} . \mathrm{s}^{-1}$ (i.e. for a gas flowrate $Q_{G}$ between 600 and $2800 \mathrm{~m}^{3} \cdot \mathrm{h}^{-1}$ ) and four liquid flowrates $\mathrm{Q}_{\mathrm{L}}$ (Fig. 2). This parameter strongly increased with $\mathrm{U}_{\mathrm{SG}}$ and with a minor extent with $\mathrm{Q}_{\mathrm{L}}$. As gas is the continuous phase, it plays a major role. Consequently, small variations of $\mathrm{U}_{\mathrm{SG}}$ can generate important variations of the pressure drop, which is an important criterion to consider for the process economic viability. The pressure drop per reactor height unit $(\Delta \mathrm{P} / \mathrm{H})$ could be well correlated to the gas and liquid superficial velocities $U_{S G}$ and $U_{S L}$ (Sanchez et al., 2007a):

$$
\frac{\Delta \mathrm{P}}{\mathrm{H}}\left(\text { mbar.m } \mathrm{m}^{-1}\right)=2.857 \times \mathrm{U}_{\mathrm{SG}}{ }^{1.68} \times\left(\mathrm{U}_{\mathrm{SL}}\right)^{0.47}=0.119 \times \mathrm{U}_{\mathrm{SG}}{ }^{2.15} \times\left(\frac{\mathrm{L}}{\mathrm{G}}\right)^{0.47}
$$

The correlation coefficient between the experimental and the predicted pressure drops is $99.94 \%$. The exponent on $\mathrm{U}_{\mathrm{SG}}$ of 1.68 confirms high dependence between the pressure drop and $\mathrm{U}_{\mathrm{SG}}$.

Figure 2. Pressure drop inside Aquilair Plus ${ }^{\mathrm{TM}}$ versus $\mathrm{U}_{\mathrm{SG}}$ for different $\mathrm{Q}_{\mathrm{L}}$.



Through the transparent PVC pipe reactor, a strong dispersion of the liquid into small droplets was observed for $U_{S G}$ higher than 13-14 m.s ${ }^{-1}$. It is interesting to notice that when the liquid flowrate increased, this dispersion regime appeared for a lower $\mathrm{U}_{\mathrm{SG}}$.

\section{$\mathrm{H}_{2} \mathrm{~S}$ removal}

Choice of the working $\mathrm{pH}$ range. Experiments carried out for $\mathrm{pH}$ varying between 9.5 and 11 showed that the $\mathrm{H}_{2} \mathrm{~S}$ removal is not significantly different (not presented here). However, for a $\mathrm{pH}$ 
close to 9.5, the formation of a yellow precipitate of colloidal sulphur was observed whereas for a $\mathrm{pH}$ close to 11, the formation of a white precipitate of carbonates could be noticed (due to the reaction between $\mathrm{NaOH}$ and $\mathrm{CO}_{2}$ present in atmospheric air). Consequently, all the following experiments were performed with a $\mathrm{pH}$ ranging between 10 and 10.5.

Influence of the superficial gas velocity on the $\mathrm{H}_{2}$ S removal. Figure 3 shows that a higher $\mathrm{U}_{\mathrm{SG}}$ induces a better $\mathrm{H}_{2} \mathrm{~S}$ removal. When $\mathrm{U}_{\mathrm{SG}}$ increases, it induces a higher dispersion of the liquid and a higher mixing of both phases. As a consequence, droplets are smaller, which means that $a^{0}$ increases, and $\mathrm{k}_{\mathrm{L}}$ is higher. For example, at the laboratory, it has been shown that $\mathrm{a}^{0}$ and $\mathrm{k}_{\mathrm{L}}$ were respectively proportional to $\mathrm{U}_{\mathrm{SG}}^{0,72}$ and $\mathrm{U}_{\mathrm{SG}}^{1,11}$ (Sanchez et al., 2007a). According to Eq. (1), the $\mathrm{H}_{2} \mathrm{~S}$ transferred flow is proportional to $\mathrm{k}_{\mathrm{L}}$ and $\mathrm{a}^{0}$, which explain the increase of the $\mathrm{H}_{2} \mathrm{~S}$ removal with $\mathrm{U}_{\mathrm{SG}}$. Nevertheless, working at high superficial gas velocities is not a cost effective solution as the pressure drop climbs. Consequently, a superficial gas velocity ranging between 14 and $15 \mathrm{~m} . \mathrm{s}^{-1}$ $\left(\mathrm{Q}_{\mathrm{G}}\right.$ from 1600 to $\left.1700 \mathrm{~m}^{3} \cdot \mathrm{h}^{-1}\right)$ was selected for all the next experiments.

Figure 3. $\mathrm{H}_{2} \mathrm{~S}$ removal and pressure drop versus $\mathrm{U}_{\mathrm{SG}}\left(\mathrm{L} / \mathrm{G}=3.5 ; 40<\left[\mathrm{H}_{2} \mathrm{~S}\right]_{\mathrm{G}, \mathrm{i}}<50\right.$ ppmv; $[\mathrm{NaOCl}] \approx 1.5$ g. $\left.\mathrm{L}^{-1} ; 10<\mathrm{pH}<10.5\right)$.

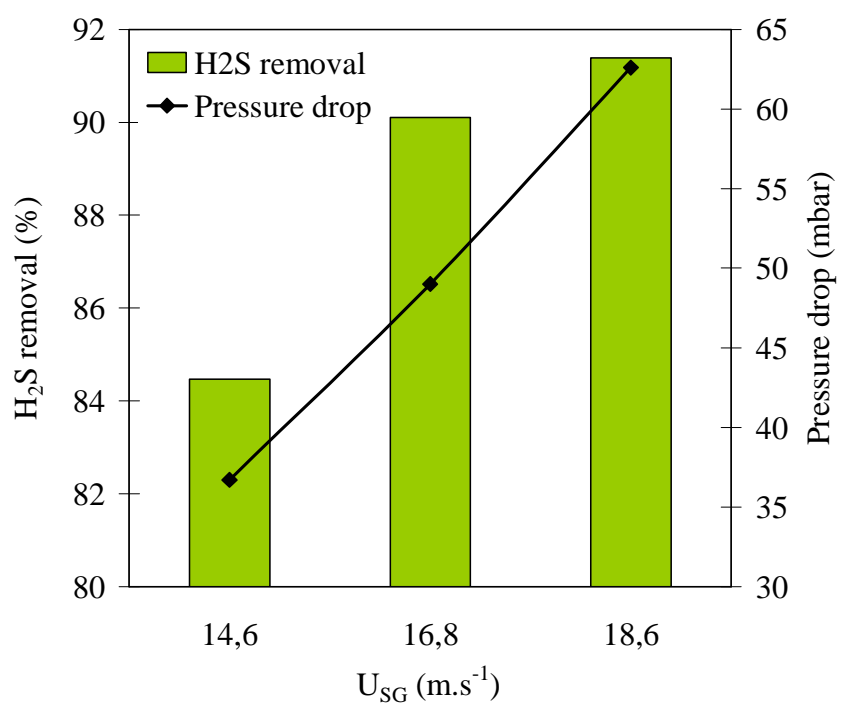

Influence of the $L / G$ ratio on the $H_{2} S$ removal.

Figure 4. $\mathrm{H}_{2} \mathrm{~S}$ removal and pressure drop versus $\mathrm{L} / \mathrm{G}$ ratio $\left(\mathrm{U}_{\mathrm{SG}}=15 \mathrm{~m} \cdot \mathrm{s}^{-1} ; 40<\left[\mathrm{H}_{2} \mathrm{~S}\right]_{\mathrm{G}, \mathrm{i}}<50 \mathrm{ppmv}\right.$; $10<\mathrm{pH}<10.5$ ).

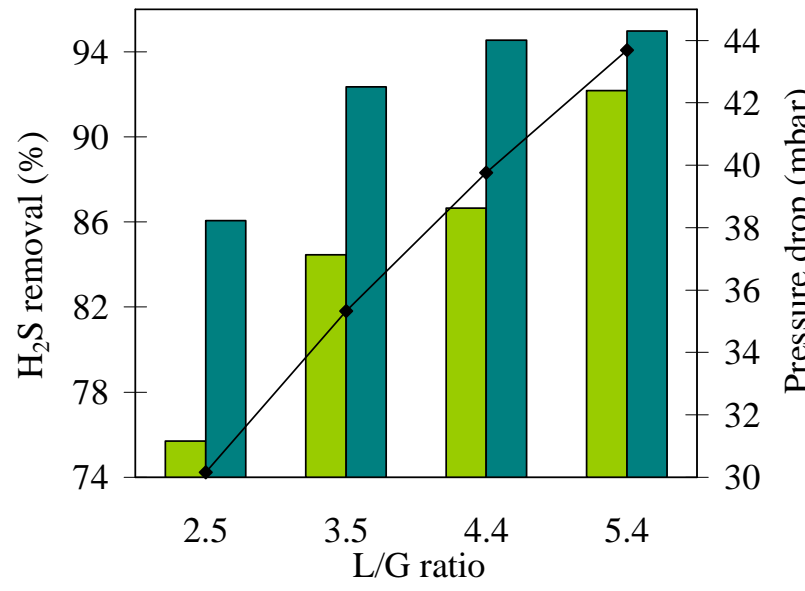

$\square$ H2S removal : $[\mathrm{NaClO}]=1 \mathrm{~g} / \mathrm{L}$
$\square \mathrm{H} 2 \mathrm{~S}$ removal : $[\mathrm{NaClO}]=2.5 \mathrm{~g} / \mathrm{L}$
$\rightarrow-$ Pressure drop

To achieve the $\mathrm{H}_{2} \mathrm{~S}$ chemical scrubbing in a packed column, $\mathrm{L} / \mathrm{G}$ is generally close to 3 , which 
means that the volumetric gas flowrate is approximately 300 times greater than the volumetric liquid flowrate. Figure 4 demonstrates that an increase of $L / G$ at a given gas flowrate induces a significant better $\mathrm{H}_{2} \mathrm{~S}$ removal. This evolution could be attributed to better hydrodynamic and thermodynamic conditions. Sanchez et al. (2007a) demonstrated at the laboratory scale that $\mathrm{k}_{\mathrm{L}} \mathrm{a}^{0}$ increases with the liquid velocity (or flowrate). Moreover, a higher L/G implies that more $\mathrm{H}_{2} \mathrm{~S}$ can be solubilised in the liquid phase and that more reagents are present in the contactor. However, increasing the liquid flowrate generates a higher pressure drop and consumes more electrical power for the recirculation, which leads to a more expensive operation. Experiments done at moderate $\mathrm{U}_{\mathrm{SG}}$ (14.1 m.s ${ }^{-1}$ ) and with $\mathrm{L} / \mathrm{G}=5.4$ allowed to reach a $\mathrm{H}_{2} \mathrm{~S}$ removal close to $95 \%$ with a rather low pressure drop of 39 mbar (not represented here).

Influence of the sodium hypochlorite concentration on the $\mathrm{H}_{2} \mathrm{~S}$ removal. As well as hydrodynamic conditions, chemical conditions can notably influence the $\mathrm{H}_{2} \mathrm{~S}$ removal. No significant variation of the $\mathrm{H}_{2} \mathrm{~S}$ removal was observed when the $\mathrm{pH}$ of the scrubbing liquid was low $(\mathrm{pH}=10)$ or high $(\mathrm{pH}$ $=11)$. Nevertheless, Figure 5 demonstrates a positive influence of the sodium hypochlorite concentration on the $\mathrm{H}_{2} \mathrm{~S}$ removal. This result is particularly interesting considering that it is a low cost operating solution.

Figure 5. $\mathrm{H}_{2} \mathrm{~S}$ removal versus $[\mathrm{NaOCl}]\left(\mathrm{U}_{\mathrm{SG}}=15 \mathrm{~m} \cdot \mathrm{s}^{-1} ; \mathrm{L} / \mathrm{G}=5.4 ; 40<\left[\mathrm{H}_{2} \mathrm{~S}\right]_{\mathrm{G}, \mathrm{i}}<50 \mathrm{ppmv}\right.$; $10<\mathrm{pH}<10.5 ; \Delta \mathrm{P}=44$ mbar $)$.

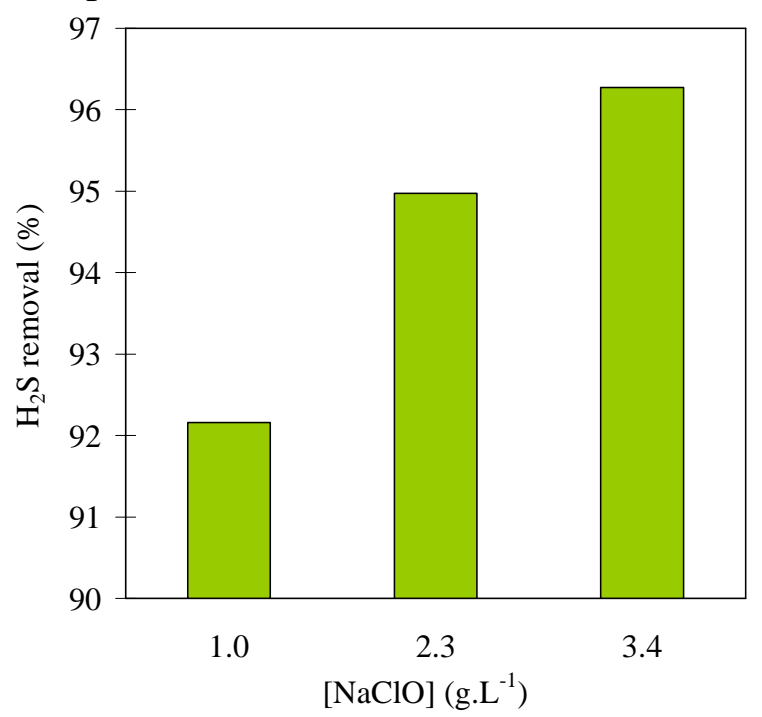

Generally, during chemical scrubbing of acidic compounds, the dissociation reactions carried out are more efficient than oxidation reactions for enhancing mass transfer due to faster kinetics (Chen et al., 2001; Couvert et al., 2006). In this case, the role of the oxidant is to degrade the pollutant in order to recycle the scrubbing liquid and to maintain a driving force for the pollutant mass transfer. Nevertheless, during the $\mathrm{H}_{2} \mathrm{~S}$ removal in the presence of sodium hypochlorite, the oxidation reaction could be more efficient than the dissociation reaction to accelerate mass transfer. Indeed, the reaction between $\mathrm{H}_{2} \mathrm{~S}$ and $\mathrm{ClO}^{-}$at basic $\mathrm{pH}$ is really fast according to the kinetic constant of $1.8 \times 10^{8} \mathrm{~L}_{\mathrm{mol}} \mathrm{m}^{-1} \cdot \mathrm{s}^{-1}$ found by Bonnin (1991). This could be easily demonstrated by comparing the Hatta numbers of each reaction (Eq. 5-8):

$$
\begin{aligned}
& \mathrm{Ha}_{\text {ox }}=\frac{\sqrt{\mathrm{k}_{\mathrm{ox}, \mathrm{H}_{2} \mathrm{~S}} \cdot\left[\mathrm{ClO}^{-}\right] \cdot \mathrm{D}_{\mathrm{H}_{2} \mathrm{~S}}}}{\mathrm{k}_{\mathrm{L}}} \\
& \Rightarrow\left(\frac{\mathrm{Ha}_{\text {diss }}}{\mathrm{Ha}_{\text {ox }}}\right)^{2}=\frac{\mathrm{k}_{\text {diss, } \mathrm{H}_{2} \mathrm{~S}} \cdot\left[\mathrm{HO}^{-}\right]}{\mathrm{k}_{\mathrm{ox}, \mathrm{H}_{2} \mathrm{~S}} \cdot\left[\mathrm{ClO}^{-}\right]}
\end{aligned}
$$

(5) and $\mathrm{Ha}_{\text {diss }}=\frac{\sqrt{\mathrm{k}_{\mathrm{diss}, \mathrm{H}_{2} \mathrm{~S}} \cdot\left[\mathrm{HO}^{-}\right] \cdot \mathrm{D}_{\mathrm{H}_{2} \mathrm{~S}}}}{\mathrm{k}_{\mathrm{L}}}$ 
$\mathrm{k}_{\mathrm{diss}, \mathrm{H}_{2} \mathrm{~S}}$ can be taken equal to $5.4 \times 10^{8} \mathrm{~L} \cdot \mathrm{mol}^{-1} \cdot \mathrm{s}^{-1}$ (Bonnin, 1991). In a first approximation, without considering the ionic strength of the scrubbing liquid, $\left[\mathrm{HO}^{-}\right]$is equal to $10^{\mathrm{pH}-14}$ and varies between $1.0 \times 10^{-4}$ and $3.2 \times 10^{-4}$ mol. $\mathrm{L}^{-1}$. Considering $\left[\mathrm{ClO}^{-}\right]=1 \mathrm{~g}_{\mathrm{Cl}} \cdot \mathrm{L}^{-1}$, it leads to:

$0.01<\left(\frac{\mathrm{Ha}_{\text {diss }}}{\mathrm{Ha}_{\text {ox }}}\right)^{2}<0.03$

When two distinct reactions can occur, the global $\mathrm{Ha}\left(\mathrm{Haglo}_{\mathrm{glo}}\right)$ can be estimated by Eq. (9):

$\mathrm{Ha}_{\text {glo }}{ }^{2}=\mathrm{Ha}_{\mathrm{ox}}{ }^{2}+\mathrm{Ha}_{\text {diss }}{ }^{2}=\mathrm{Ha}_{\mathrm{ox}}{ }^{2}\left(1+\left(\frac{\mathrm{Ha}_{\text {diss }}}{\mathrm{Ha}_{\mathrm{ox}}}\right)^{2}\right) \approx \mathrm{Ha}_{\mathrm{ox}}{ }^{2}$

Consequently, the mass transfer enhancement in our chemical conditions can be attributed to oxidation reaction. Nevertheless, $\mathrm{HO}^{-}$anions play a fundamental role during the scrubbing step

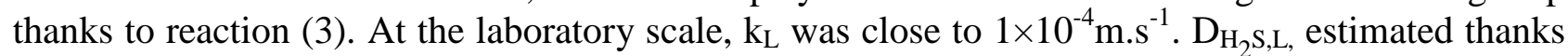
to the Wilke and Chang correlation (Perry and Green, 1997), is equal to $1.41 \times 10^{-9} \mathrm{~m}^{2} . \mathrm{s}^{-1}$. This leads to a Hatta number of approximately 850 for $[\mathrm{NaOCl}]=1 \mathrm{~g}_{\mathrm{Cl}} \cdot \mathrm{L}^{-1}$. This confirms that $\mathrm{H}_{2} \mathrm{~S}$ reacts completely in the liquid film, and that its removal strongly depends on the $\mathrm{NaOCl}$ concentration.

Influence of the $\mathrm{H}_{2} \mathrm{~S}$ gaseous concentration. Several experiments were done for $\mathrm{U}_{\mathrm{SG}}=14.1 \mathrm{~m} \cdot \mathrm{s}^{-1}$, $\mathrm{L} / \mathrm{G}=5.5,10<\mathrm{pH}<10.5$ and $[\mathrm{NaOCl}] \approx 3 \mathrm{~g} . \mathrm{L}^{-1}$, but with $\left[\mathrm{H}_{2} \mathrm{~S}\right]_{\mathrm{G}, \mathrm{i}}$ varying from 6 to $80 \mathrm{ppmv}$. The $\mathrm{H}_{2} \mathrm{~S}$ removal was not significantly different and close to $96 \%$. It was not possible to study a lower $\left[\mathrm{H}_{2} \mathrm{~S}\right]_{\mathrm{G}, \mathrm{i}}$ because the detection level of the electrochemical sensor Polytron was reached at the outlet. With a classical $\mathrm{H}_{2} \mathrm{~S}$ inlet concentration in WWTP of 5-6 ppmv, it is consequently possible to reach an $\mathrm{H}_{2} \mathrm{~S}$ outlet concentration ranging between 0.1 and $0.2 \mathrm{ppmv}$, which is acceptable.

\section{Reagent consumption of the process}

The $\mathrm{NaOCl}$ and $\mathrm{NaOH}$ consumptions were estimated considering the functioning time of each reagent metering pump, the concentration of each reagent solution and the duration of each experiment ( 1 hour on average). The consumption was about $6.1 \mathrm{~mol}$ of $\mathrm{NaOCl}$ and $3.0 \mathrm{~mol}$ of $\mathrm{NaOH}$ per mol of $\mathrm{H}_{2} \mathrm{~S}$ transferred whereas the theoretical consumptions are equal to 4 and 2 moles respectively. This over-consumption could not be justified by the absorption/reaction of other species since $\mathrm{H}_{2} \mathrm{~S}$ was the only one detected. Indeed, a sample of the inlet polluted gas was analysed, after concentration on Tenax Tube, by Gas chromatography (Agilent 300) coupled with Mass Detection (Agilent 5973N) (Injector temperature: $90^{\circ} \mathrm{C}$; column temp.: $110^{\circ} \mathrm{C}$ for 30 psi; carrier gas: helium; mass detection in scan mode; source temp.: $250{ }^{\circ} \mathrm{C}$; column OV1: $40 \mathrm{~m} \times 0.15 \mathrm{~mm} \times 2 \mu \mathrm{m})$. At the laboratory scale, the reagent consumption was lower than the theoretical one (Couvert et al., 2008a). Nevertheless, no recirculation of the scrubbing liquid was implemented and the consumption was calculated between inlet and outlet of the contactor. As the residence time is identical between the contactors of both studies $(50 \mathrm{~ms})$, it seems to be obvious that the over-consumption observed in the pilot plant takes place in the storage tank. Indeed, in this part of the pilot $(\varnothing=900 \mathrm{~mm})$, which is dedicated to the gas-liquid separation, the interface between gas and liquid is high, and mass transfer between phase can occur. Then, the $\mathrm{NaOH}$ consumption could be attributed to the absorption of $\mathrm{CO}_{2}$ present in atmospheric air above the scrubbing liquid in the tank and the $\mathrm{NaOCl}$ consumption to stripping from the liquid to the air. Some improvements of the storage tank design should allow to decrease the over consumption in limiting the interface between the treated gas and the scrubbing liquid.

\section{CONCLUSION}

A new compact chemical scrubber was implemented in a WWTPs. Results showed that both hydrodynamic and chemical conditions significantly influence the $\mathrm{H}_{2} \mathrm{~S}$ removal. An interesting economic compromise was deduced for a moderate gas velocity and a high hypochlorite 
concentration. A great advantage of this contactor is that high variations of the gas flowrate can be supported without any risk of flooding. This study demonstrated the feasibility of compact scrubbing at large scale where there is lower wall effect than at the laboratory scale. The new packing has not been optimised yet and some improvement of the structure would certainly offer a lower pressure drop for a similar mass transfer rate.

\section{REFERENCES}

Bonnin C. (1991). Les sources de nuisances olfactives dans les stations de traitement des eaux usées résiduaires, et leur traitement par lavage à l'eau chlorée en milieu basique (Sources of olfactory nuisances in wastewater treatment plants and their treatment by chemical scrubbing with an alkaline chlorinated solution). PhD thesis, Ecole Nationale Supérieure de Chimie de Rennes, Université de Rennes I, Rennes, France.

Cadena F. and Peter R. (1988). Evaluation of chemical oxidizers for hydrogen sulfide control. Journal- Water Pollution Control Federation, 60(7), 1259-1263.

Chen L., Huang J. and Yang C.-L. (2001). Absorption of $\mathrm{H}_{2} \mathrm{~S}$ in $\mathrm{NaOCl}$ caustic aqueous solution. Environmental Progress, 20(3), 175-181.

Coulson J. M. and Richardson J. F. (1996). Coulson and Richardson's chemical engineering - Fluid flow, heat transfer and mass transfer. Pergamon, New-York.

Couvert A., Charron I., Laplanche A., Renner C., Patria L. and Requieme B. (2006). Treatment of odorous sulphur compounds by chemical scrubbing with hydrogen peroxide - Application to a laboratory plant. Chemical Engineering Science, 61(22), 7240-7248.

Couvert A., Sanchez C., Laplanche A. and Renner C. (2008a). Scrubbing intensification for sulphur and ammonia compounds removal. Chemosphere, 70(8), 1510-1517.

Couvert A., Sanchez C., Laplanche A., Renner C. and Levasseur J. P. (2008b). Design of a new compact scrubber for deodorisation. Chem. Eng. and Proc.: Proc. Intens., 47(9-10), 1793-1798.

Frechen F. B. (2004). Odour emission inventory of German wastewater treatment plants-odour flow rates and odour emission capacity. Water Science \& Technology, 50(4), 139-146.

Gostelow P., Parsons S. A. and Stuetz R. M. (2001). Odour measurements for sewage treatment works. Water Research, 35(3), 579-597.

Levenspiel O. (1999). Chemical reaction engineering- $3^{\text {rd }}$ edition. John Wiley \& Sons, New York.

Matos J. S. and de Sousa E. R. (1992). Forecasting of hydrogen sulphide gas build-up in sewerage collection systems. Water Science \& Technology, 26(3), 915-922.

Nielsen P. H., Raunkjær K. and Hvitved-Jacobsen T. (1998). Sulfide production and wastewater quality in pressure mains. Water Science and Technology, 37(1), 97-104.

Perry R. H. and Green D. W. (1997). Perry's chemical engineers' handbook, 7th edition. McGrawHill, New-York.

Sanchez C., Couvert A., Laplanche A. and Renner C. (2007a). Hydrodynamic and mass transfer in a new co-current two-phase flow gas-liquid contactor. Chem. Eng. J., 131(1-3), 49-58.

Sanchez C., Couvert A., Laplanche A. and Renner C. (2007b). New compact scrubber for odour removal in wastewater treatment plants. Water science and technology, 54(9), 45-52.

Sanchez C., Couvert A. and Renner C. (2007c). Device for treating a gaseous effluent loaded with odorant compounds using a three-dimensional mesh, corresponding installation and process. patent WO 2007/063104 A1, OTV, France.

Van Krevelen D. W. and Hoftijzer P. J. (1948). Kinetics of gas-liquid reactions. Part I. General Theory, Rec. Trav. Chim, 67(-), 563-586. 